\title{
The societal embedding of sustainable Product-Service Systems \\ Looking for synergies between strategic design and transition studies
}

\section{Fabrizio Ceschin}

Politecnico di Milano, DESIGN Department, Design and system Innovation for Sustainability (DIS) unit of research, Italy

Brunel University, School of Engineering and Design, Department of Design, UK

\subsection{The problem of implementing and diffusing eco-efficient PSSs}

A wide variety of research projects in the field of PSS and sustainability supported by EU funding in the last 15 years have contributed to a better understanding of the concept of eco-efficient PSS, clarifying its characteristics, potential benefits, drivers and barriers and possible rebound effects. Moreover several methods and 
tools have been developed to support the design of eco-efficient PSSs. ${ }^{1}$ However, despite this accumulated knowledge as well as the potential win-win characteristics, the application of this concept is still limited. An important reason is that eco-efficient PSSs are in most cases radical innovations ${ }^{2}$ and the adoption of such business strategies encounters significant corporate, cultural and regulatory barriers (Ceschin 2012b).

Schot and Geels (2008) consider radical innovations always immature when they enter the market because they encounter a dominant socio-technical context (and its established and stable rules and networks of actors). Eco-efficient PSS innovations are in most cases a radical innovation (Tukker and Tischner 2006a) because they challenge existing institutions, customers' habits and lifestyles, companies' organisational structures and regulative frameworks. As a result they have high probability to be rejected under mainstream market conditions. For this reason, for those companies that do see PSS innovation as key to their future, there are still significant challenges to be faced, not only in developing a promising PSS concept, but also in understanding the contextual conditions in which it is introduced and identifying the best strategies and development pathways to implement and scale it up in the market.

Against this background the focus of this chapter is on the implementation and diffusion of eco-efficient PSSs. In particular the key questions to be addressed are as follows:

- What are the dynamics and factors that facilitate and hinder the implementation and diffusion of eco-efficient PSSs? How can the process of introduction and diffusion of this kind of innovation be effectively managed?

- What could be the role of strategic design in supporting and orienting this process?

In order to answer these questions we propose to learn from the field of innovation studies and in particular from the field of transition studies. Recent explorations in these fields (in particular the contributions from Strategic Niche Management and

1 For example the Kathalys method for sustainable product-service innovation (Luiten, Knot and van der Horst 2001); DES, Design of eco-efficient services methodology (Brezet et al. 2001); PSS innovation scan for industry (Tukker and van Halen 2003); HiCS, Highly Customerised Solutions (Manzini, Collina and Evans 2004); MEPSS, Methodology for Product Service System development (van Halen, Vezzoli and Wimmer 2005); Practical guide for PSS development (Tukker and Tischner 2006b); SPSD, Sustainable Product Service Development (Maxwell, Sheate and van der Vorst 2006); Modular design for technical PSS (Aurich, Fuchs and Wagenknecht 2006); MSDS, Method for System Design for Sustainability (Vezzoli, Ceschin and Cortesi 2009; Vezzoli 2010), described in Part 1, Chapter 4 .

2 It must be underlined that not all eco-efficient PSSs are radical innovations. PSSs providing enabling platforms and PSSs providing final results (in particular in the B2C sector) can usually be considered radical innovations. 
Transition Management approaches) have focused on socio-technical transitions and how to facilitate the introduction and diffusion of radical innovations. According to these theories, the introduction of radical innovations requires the creation of partially protected socio-technical experiments, shielded from the mainstream market selection environment to allow incubation and maturation. This chapter explores how these theories can provide insights to manage the process of introducing and diffusing eco-efficient PSSs and what role strategic design can play in this process.

\subsection{Insights from transition studies}

Transition theorists refer to system or radical innovations as major changes in the ways societal functions such as transportation, communication, housing and feeding are fulfilled (Rip and Kemp 1998; Geels 2002). System innovations are complex and long-term processes that require changes in the social, economic, technological and policy domains. Through historical socio-technical case studies, transition scholars have analysed how system innovations take place and have elaborated a model called the multi-level perspective on transitions (Geels 2002) that describes the dynamics regulating these complex and long-term processes. The multi-level perspective distinguishes three analytical concepts (Geels 2002):

- The socio-technical regime, which can be defined as the dominant way of innovating, producing, distributing and consuming, etc. It refers to a dynamically stable set of culture, practices and institutions (Rotmans et al. 2001) related to a specific field (e.g. mobility or energy). Regimes are relatively stable and resistant to change because their practices, rules and institutions guide regime actors in a specific direction discouraging the development of alternatives

- The niche, a protected space that is 'isolated' from the influence of the dominant regime, where radical innovations can be tested and nurtured, become more mature, and potentially challenge and change regime practices and institutions

- The landscape, that is, the relatively stable social, economic and political context in which actors interact and regimes and niches evolve. It represents the background for regimes and niches. It includes structural socioeconomic, demographic, political and international developments, but also events such as wars or environmental disasters. It can influence the regime and the niches but cannot be influenced by them (at least in the short term) 
The distinction between the three levels is analytical and not ontological; in other words the levels are useful for categorising and better understanding socio-technical changes rather than being real entities 'out there' (Raven et al. 2010). What is important to underline is that transitions occur through the fruitful coupling of developments at all three levels (Rip and Kemp 1998; Geels 2002): when the regime is sufficiently open to accept radical innovations; when there is sufficient pressure from the landscape for change; and when radical innovations have been developed in niches that can be used to exploit the opportunities for change (Raven et al. 2010).

Niches are therefore a fundamental part of transitions but not sufficient. Moreover, even if niche developments can hold great promise, they do not immediately live up to expectations because they are immature when they enter the market and because they conflict with the way society is organised. In this sense, if immediately exposed to market competition, it is highly probable they will not survive. For these reasons a protected space should be created where continuous experiments can bring them to maturity (Schot and Hoogma 1996). Niches can thus act as 'incubation rooms' for radical novelties (Geels 2002), where experimentations and learning processes take place.

An important prerequisite to the introduction of radical innovations is the creation of partially protected socio-technical experiments (Kemp et al. 1998, Hoogma et al. 2002; Van der Laak et al. 2007; Brown and Vergragt 2008; Raven et al. 2010; Van den Bosch 2010). These protected experiments allow the incubation and maturation of radical socio-technical configurations by partly shielding them from prevailing cultural, organisational and regulatory rules (the incumbent socio-technical regime). Sequences of socio-technical experiments can be used as a strategic arena for experimenting, learning, shaping future expectations and establishing new social networks in order to gain momentum for diffusion and challenge and change prevailing regimes (Raven 2005).

The use of experiments is recognised to be crucial also in innovation management studies. For Laredo et al. (2002) the development of radical innovation projects cannot be explained in terms of a sequence of states (e.g. concept, pilot, prototype, and industrial development) which projects are expected to go through but rather in terms of trials that projects subject themselves to in the course of progressively testing the innovation characteristics. Latour (2000) defines these kinds of trials as collective experiments or socio-technical demonstrations, the role of which is to test the technical, social, political and economic configuration of the innovation. Along the same line, Brown et al. (2003) underline the importance of small-scale Bounded Socio-Technical Experiments (BSTE), while Lynn et al. (1996) speak about the 'probing and learning' strategy: market try-outs with early prototypes used as a vehicle for learning about the new technology in its real life context, followed by adjustment in technology design and marketing approach. (At the same time the 
exposure to early prototypes influences the expectations, needs and behaviour of potential customers and other stakeholders.)

In sum socio-technical experiments represent an important strategic opportunity to initiate and foster wider transition processes. How exactly these experiments can successfully bring about the diffusion of radical alternatives has been more deeply investigated in the field of Strategic Niche Management (SNM), which individuates three key internal processes (Kemp et al. 1998; 2001; Hoogma 2000; Hoogma et al. 2002).

The first process is the establishment and development of a broad socioeconomic network. A broad network means it includes not only the actors more directly linked with the innovation (such as firms, partners and users) but also other relevant actors from the science, policy and societal domains (e.g. research centres, governmental institutions, NGOs and special interest groups) ${ }^{3}$ (Raven 2005). In other words it should be a heterogeneous network with relevant scientific, social, economic, political and cultural actors, including:

- Those that can mobilise knowledge and financial and managerial resources to develop such alternative innovations (such as outsider firms) (Van de Poel 2000)

- Those that can introduce new designs, criteria, approaches and concepts (such as scientists, research centres, and universities) (Van de Poel 2000)

- Those that can give experiments legitimacy and stability (such as governmental institutions)

- Those that have the power and willingness to directly influence the dominant culture, practices and institutions (such as ministries, policy-makers and politicians) (van den Bosch 2010)

- Those that may (in)directly influence the regime because they have an interest in embedding new sustainable practices in society (such as NGOs, lobby groups, and consumer groups) (van den Bosch 2010)

- Those that can spread information on the innovation (such as media, opinion leaders and NGOs)

- Those that may support the scaling-up of the innovation (such as potential industrial partners, industrial associations or consortia)

3 This is coherent with what has been argued by some radical innovation scholars; for example Callon (1991) underlines the importance of involving 'a coordinated set of heterogeneous actors-laboratories, technical research centres, financial organisations, users, and public authorities - which participate collectively in the development and diffusion of innovations, and which organise, via numerous interactions, the relationships between research and the market place'. Callon (1991), Callon et al. (1992), and Laredo and Mustar (1996) refer to this set of heterogeneous actors as the 'techno-economic network'. 
Second, a key process is the convergence of actors' expectations into a shared long-term vision. As mentioned, the process of experimenting with and embedding radical innovations in society requires the involvement of many actors from different domains, who may hold different expectations about a particular innovation. Therefore it becomes fundamental to manage the diversity of expectations and their negotiation and alignment (Raven et al. 2008). This convergence helps give strategic orientation and legitimacy to the innovation development (Kemp et al. 1998; Raven 2005) but also can attract new actors and resources (Raven 2005). The creation of a shared project vision can contribute to articulating expectations, formulating agendas and action plans, and coordinating the strategies of the actors involved (Kemp and Rotmans 2004). Future scenarios and visions are in fact crucial to committing actors and orienting their actions (De Laat 1996; Akrich 1992; Berkhout 2006; Quist et al. 2006). It must however be emphasised that expectations are not fixed (Van Lente 1993; Hoogma 2000; Raven 2005): actors can change their views and expectations, as a result of the negotiation processes with other actors but also in reaction to changes in the external environment. As a consequence it is fundamental to continuously refine and re-orient the project vision (i.e. a flexible vision open to adjustment).

The third key process is an effective learning process among the actors involved. Learning takes place when individuals assimilate new information and apply it to their subsequent actions (Hall 1993). It is therefore crucial in the process of inducing change towards the adoption and diffusion of radical innovations, in which new basic beliefs, behaviours and rules are required (Van de Kerkhof and Wieczorek 2005). An adequate learning process is considered key because it enables adjustments of the innovation and increases chances for a successful diffusion (Raven $e t$ al. 2010). An adequate and effective learning process should be:

- Broad (Weber et al. 1999; Raven 2005), focusing on many dimensions of the problem: not only the technical and economic aspects of the innovation, but also the cultural (societal beliefs, values and habits), regulative (government policy and regulatory frameworks), and institutional (rules and norms) dimensions

- Reflexive (Hoogma and Schot 2001; Raven 2005), implying that both first and second order learning occur. First order learning can result in a correction or resolution of a certain problem (e.g. technical issues). Second order learning (Hall 1993) leads to a paradigm shift, which refers to a change in the problem definition, basic assumptions, norms, values and interpretive frames which govern the decision-making process of individuals, communities and organisations

The better these three processes are managed, the greater the possibility that experiments can develop into a market niche, influence and transform the existing regime or become a viable alternative to it. 


\subsection{A conceptual framework for the implementation and diffusion of eco-efficient PSSs}

Even though the school of transition studies uses a more sociological approach (looking at the actors involved, consumer expectations, etc.), it is commonplace to take a technological artefact as the starting point and see social developments as a derivative of technological innovation (Hegger et al. 2007). An eco-efficient PSS is not a technological innovation; of course it can include technological artefacts, but the innovative element is mainly related to the social dimension. In fact, rather than a new technological artefact, an eco-efficient PSS can be seen as a new form of social organisation. Hence, a crucial question is this: are the insights from transition studies valuable also for the specificities of eco-efficient PSS innovations? Can they be extended to manage the introduction and diffusion not only of technological innovations but also of eco-efficient PSS innovations?

A research case study that investigated the innovation journeys made by six companies introducing their eco-efficient PSS concepts to the market confirmed this hypothesis (Ceschin 2012a, b). Building upon the results of this case study a conceptual framework for the implementation and diffusion (introduction and scaling-up) of eco-efficient PSSs can be drawn up (see Figure 4.1). In synthesis, the entry point of an eco-efficient PSS innovation is a project vision (I): a PSS idea or concept developed to overcome a societal/environmental/business challenge. This project vision provides a direction for the societal embedding process (II), in which a broad network of actors (III) experiments and learns how the project vision can be realised. The societal embedding process is based on the implementation of small-scale socio-technical experiments, the development and empowerment of a niche, and the scaling up of the PSS innovation (and its related new set of culture, practices and institutions) in the regime. The process is characterised by dynamic adaptation: what is learnt by actors leads to a continuous and mutual adjustment of the project vision, the transition path, and the actor network itself (IV).

In other words the process of introducing and scaling-up eco-efficient PSS innovations should be managed as a process in which design, developing, testing and implementing are activities carried out simultaneously. In this sense the learningby-doing approach should be the underlying philosophy.

Within this process setting up sequences of socio-technical experiments is a promising strategy to support, speed up and orient the incubation, testing and maturation of radical innovations. In other words the process of introducing and scaling up eco-efficient PSSs should be seen as a transition path, characterised by: 
Figure 4.1 Conceptual framework for the introduction and scaling-up of eco-efficient PSS concepts

Source: Ceschin 2012a

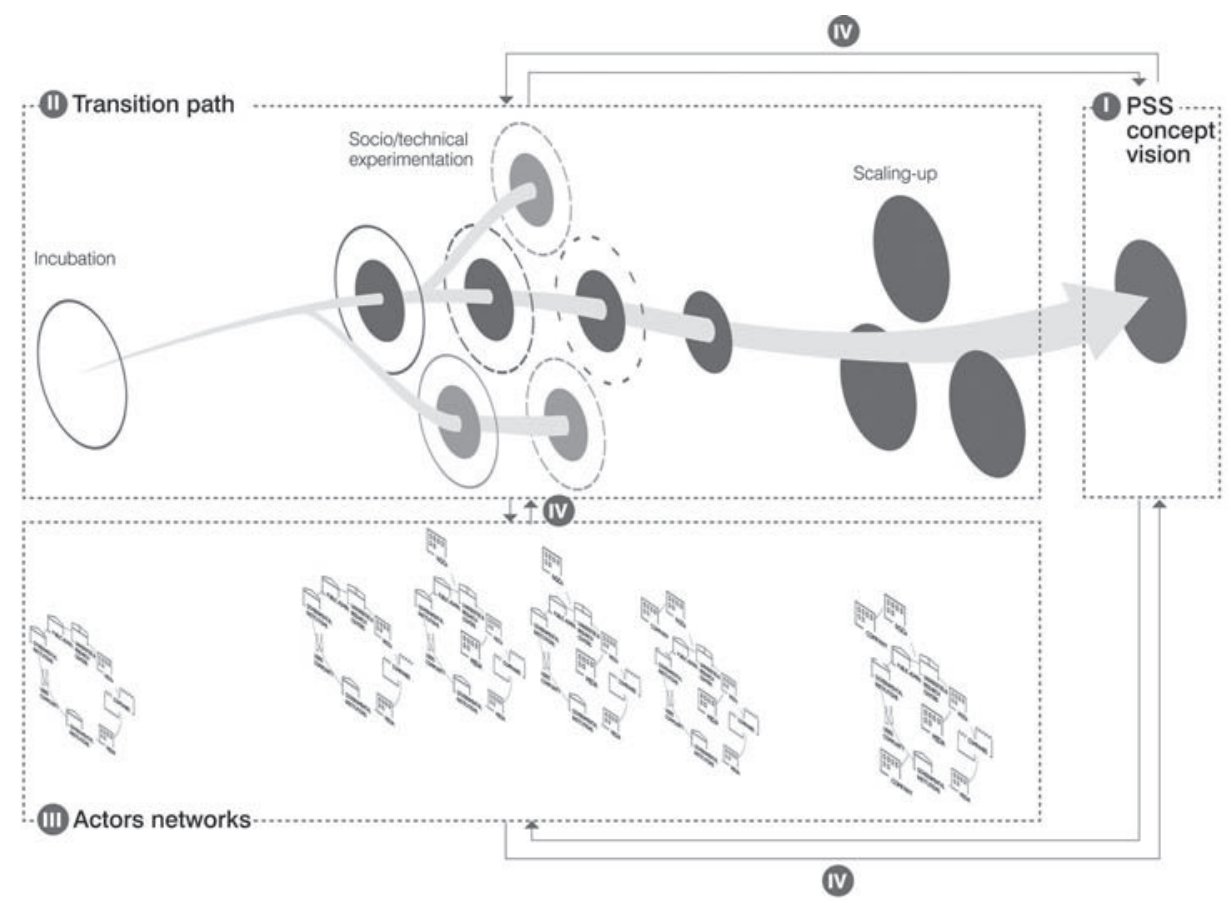

- An incubation phase, in which the conditions needed to start the societal embedding process are understood (identification and involvement of needed actors; discussion and negotiation to achieve a common consensus on the PSS concept as well as on the potential strategies to socially embed the concept)

- A socio-technical experimentation phase, in which sequences of experiments take place with the aim of learning and exploring how to improve the PSS innovation and how to contribute to its societal embedding

- A scaling-up phase, in which the PSS innovation (and the related new practices, behaviours and institutions) increases its momentum and starts to influence the socio-technical regime (i.e. the initially unusual PSS innovation increasingly becomes part of the dominant way in which a societal need/ desire is satisfied)

In this transition process a crucial role is played by the establishment and development of a proper network of actors: a broad and dynamic network able to protect, support and foster the innovation. This wide network should involve not only the actors belonging to the PSS value chain (e.g. producer, partners and suppliers, and customers/users) but also other actors: for instance universities and research 
centres (that can give scientific support), institutions and public administrations (that can promote the innovation and give political support), NGOs (that can be partners of the project), and also media (that can give visibility to the innovation). The dynamism of this network must be underlined: the composition and even the role of each actor evolve in time. For instance some actors may have more relevance in the first phases and disappear in the later phases (e.g. a public administration can be involved only in the beginning to provide incentives and protection to the innovation).

It is also fundamental to build up a long-term vision shared among the actors involved in the project. A shared project vision can provide direction for the societal embedding process and therefore direction for the stakeholders' actions. Project visions can therefore be used as guides to formulate strategies, but also to attract, persuade and involve new potential partners and stakeholders to join the project.

Finally, it is crucial that room is created for broad learning (learning about the PSS innovation as well as about the different dimensions of the context in which the innovation should be introduced) and reflexive learning (learning resulting in changes in actors' reference framework, beliefs, behaviours, practices etc.). Learning processes are strictly related to how experiments are designed and managed. Experiments that not only focus on exploring and testing the technical aspects, but also ones related to usability, policy, regulations, social acceptance, etc. easily lead to broad learning processes. Reflexive learning is fundamental to breaking down actors' accepted assumptions and routine behaviours and inducing changes in culture, practices and institutions.

It must be emphasised that this approach should not be seen as a 'recipe for success'. Scaling up in practice requires favourable conditions and circumstances (e.g. there should be enough pressure from the landscape, the regime should be sufficiently open to accept radical innovations, etc.). Companies or small networks of actors may not be able to directly (or indirectly) influence these conditions and circumstances. Therefore the process from incubation to scaling-up becomes increasingly more uncertain, less manageable, and more influenced by project-external events and dynamics. However the adoption of an experimental-, learning-, and network-based management approach can increase the chances of success (i.e. speed up and increase the possibilities to set up a market niche in which the innovation is commercialised). Within this process socio-technical experiments play a strategic and crucial role in the process of triggering and catalysing radical innovations. Because of their importance it is useful to clarify the concept of socio-technical experimentation and its potential to contribute to transitions.

\subsubsection{Socio-technical experiments and their importance in triggering transition processes}

A socio-technical experiment can be defined as a partially protected environment where a broad network of actors can learn and explore (I) how to incubate and improve radical innovations and (II) how to contribute to their societal embedding. 
These experiments represent strategic opportunities to develop and bring to maturity highly risky innovations such as sustainable PSSs without the direct pressure of the mainstream market selection environment. A socio-technical experiment is, however, not a simple pilot or demonstration project. ${ }^{4}$ The main characteristics of a socio-technical experiment are described below.

- First, experiments are conducted with radical innovations: innovations that require substantial changes on various dimensions (socio-cultural, technological, regulative and institutional). Not all PSSs are radical innovations and therefore not all PSSs require the adoption of a strategy based on the settingup of socio-technical experimentation

- Second, the experiments are not simple tests undertaken inside a company's laboratory but are implemented in real-life settings. The idea is that only this kind of experience, outside R\&D (Research \& Development) settings, can truly lead to testing and improving radical innovations. Moreover these experiments take place at a small scale but strive to trigger changes at a wider scale

- Third, these experiments not only include the actors more strictly linked to the innovation (such as producers, partners and suppliers). Instead, a broad variety of actors is involved, including also users, policy-makers, local administrations, NGOs, consumer groups, industrial associations, research centres, and so on. In other words the aim is to recreate a whole socio-technical environment in a small scale. In this sense these experiments are characterised by a broad participatory approach: i.e. a variety of actors is involved in discussing, negotiating, co-creating and developing the innovation

- Fourth, the experiment is implemented in a space protected from the mainstream selection environment. The idea is to temporarily shield the innovation from the selection pressure (which consists of markets and institutional factors), creating an alternative selection environment. There are different forms of protection: financial protection (such as strategic investments by companies, tax exemptions, and investment grants) and socio-institutional protection (such as the adoption of specific regulations). The crucial dilemma of protection measures is to find the right balance between the need to nurture the innovation and the need to prepare it for the selection pressures of a market environment (Weber et al. 1999)

4 The concept of socio-technical experiments, as intended here, also differs from the concept of living labs. Living labs are 'situated in real world environments, are user-driven, and collaborate with research organisations, companies, and public and civic sectors with the aim to collaboratively develop new services and products' (Björgvinsson, Ehn and Hillgren 2010). Compared to living labs, the concept of socio-technical experiments is broader. It includes not only the idea of setting up a participatory approach to developing new solutions in real-life scenarios and creating a protected space where the innovation can be incubated, but also working towards stimulating changes in the sociotechnical context. 
- The aim of these experiments is to learn about and improve the innovation on multiple dimensions, not only the technical, economic, market demand and usability aspects, but also the political, regulative, environmental, cultural and social dimensions. In this sense the innovation is maintained in order to be open to continuous adjustments and refinements. In general experiments can also serve to identify the various resistances and barriers (institutional, regulative, economic, etc.) that can potentially hinder future implementation and diffusion and understand how to address them

- Moreover, and this is a crucial aspect, socio-technical experiments are not only aimed at testing and improving the innovation, but also at stimulating changes in the socio-technical context, in order to create the most favourable conditions for the PSS innovation. In other words experiments are also strategically used to influence contextual conditions in order to favour and speed up the societal embedding process (for example, by influencing local administrations to adopt policy measures that support the innovation or stimulating potential users to change their behaviours and routines)

Within this framework three main mechanisms through which socio-technical experiments can contribute to transitions can be identified (Van den Bosch and Rotmans 2008; Van den Bosch 2010) (Figure 4.2):

- Deepening, which means learning as much as possible about an innovation within a specific context. Deepening enables actors to learn about local shifts in culture (ways of thinking, values, reference frameworks, etc.), practices (habits, ways of doing things, etc.) and institutions (norms, rules, etc.). The result of deepening is the development and reinforcement of the new set of culture, practices and institutions related to the PSS innovation

- Broadening, which means replicating the experiment in different contexts and linking it to other projects and initiatives. Since learning within an experiment is limited, experiments should be repeated in other contexts, in order to learn about different designs in different settings. Broadening is related to the idea that different experiments carried out simultaneously can build on each other and gradually reinforce themselves (Raven 2005; Geels and Raven 2006). It is also important to strengthen synergies with other local, similar projects and initiatives. Through processes of broadening, the deviant set of culture, practices and institutions is (I) tested and extended to a variety of contexts and (II) linked to other existing projects and initiatives

- Scaling-up, which means embedding the innovation in dominant ways of thinking, doing and organising. It relates to moving the innovation (and its initially new socio-technical practices) from a local experimental level to a mainstream level. As underlined by Van den Bosch (2010), scaling-up is less about scaling up products, services or users and more about scaling up perspectives, ways of thinking, routines, legislation, institutions, and so on 
On the basis of these considerations socio-technical experiments, in order to contribute to transition processes, should be conceived in order to act as the following (Ceschin 2010, 2012a; Ceschin et al. 2011) (Figure 4.2):

- Labs, to test, learn about and improve the PSS innovation on multiple dimensions (technical, usability, regulative, political, economic, and socio-cultural) and in relation to different contexts (in order to learn about different PSS configurations in different settings)

- Windows, to raise interest in the innovation project and the related actors, disseminate results, build up synergies with existing similar projects/initiatives, and attract and enrol new actors (e.g. new users or potential partners)

- Agents of Change, to influence contextual conditions in order to promote and quicken the societal embedding process. Experiments should be conceived to introduce and diffuse new ideas and knowledge to the community and stimulate various social groups (users, public institutions, companies, etc.) to change their perspectives, beliefs, and lifestyles. Experiments should in fact represent a stimulus to induce actors to change their behaviours and interpretative frames (for example, they can stimulate users to change their routines or push governmental institutions to implement proper policy measures to favour the PSS innovation)

Figure 4.2 Three main mechanisms through which socio-technical experiments can contribute to transitions (deepening, broadening and scalingup) in relation to the concepts of experiment as a Lab, Window and Agent of Change

Source: author, inspired by Van den Bosch and Rotmans (2008)






\subsection{Implications for design: a new role for strategic design for sustainability}

If an experimental-, learning-, and network-based management approach represents a promising strategy to successfully incubate, test, develop and bring to maturity eco-efficient PSSs, the questions at this point are: what are the implications at the level of design? What could the role of strategic design be?

We know that several methods and tools have been developed to support designers in ideating eco-efficient PSS concepts. However, if designers want to act as effective agents of change they should be aware of the mechanisms and dynamics that regulate the implementation and diffusion of this kind of innovation-and how it is possible to guide and orient them. In short, if designers want to play a more effective role in the transition towards sustainability, they cannot limit themselves to proposing eco-efficient PSS concepts; they should also indicate the most promising pathways for the implementation and diffusion of such radical innovations: in other words, strategic design for sustainability can also play a role in designing transition paths to support and facilitate the introduction and diffusion of the concepts it generates (Vezzoli, Ceschin and Kemp 2008; Ceschin 2010, 2012a). In this sense designers could guide and support a company, an institution or a network of actors in the process of introducing and gradually embedding eco-efficient PSS concepts in society. In order to do this a new design approach and new design capabilities are required.

\subsubsection{A new strategic design approach}

In this new approach, designers would first need to focus on a broader design scope where the ideation of sustainable PSS concepts should be coupled with the designing of appropriate transition paths. In particular the design scope should be extended to:

- The strategic design of the sequence of steps that can lead to gradually reinforcing/improving the PSS innovation and fostering its societal embedding (incubation, socio-technical experimentation, and niche development and scaling-up)

- The identification and involvement of the actors that can support the societal embedding process in the various steps of the transition path (i.e. identification of actors and related roles)

The designing of transition paths therefore requires the adoption of a multi-term design attitude. This attitude allows designers to simultaneously focus on:

- The project long-term goal: the achievement of a future in which a sustainable PSS innovation is part of the normal way in which a societal need is fulfilled (project vision) 
- The short- and medium-term actions to be undertaken in order to orient the societal embedding process towards the long-term goal

Second, a broader strategic design attitude is required. This means that strategic designers should focus not only on the PSS innovation but also on the contextual conditions that may favour or hinder the societal embedding process. Strategic designers should therefore adopt a strategic attitude oriented at making the sociotechnical context more conducive for the PSS. This is achieved by involving those actors that, directly or indirectly, could affect regime practices and institutions and/or by stimulating changes in actors' behaviours and practices. The transition path is thereby seen as a process not only aimed at testing and bringing the PSS innovation to maturity, but also aimed at influencing the socio-technical context in order to foster the societal embedding of the PSS.

Third, a broader strategic design attitude requires a broader system stakeholder approach. Strategic designers working on a PSS level are adept at adopting a system design approach. This means that their design activity is focused not only on the PSS offer (the integrated set of products and services), but also on the socio-economic stakeholders to be involved in the PSS and the relations among these stakeholders (in other words the PSS value chain or net). In this case strategic designers should focus not only on the PSS value chain but also on the socio-technical context in which the PSS should be introduced. This means that the actors to be taken into consideration are not only those more directly linked with the innovation, but also other relevant actors from the science, policy and societal domains: i.e. a broad network characterised by scientific, social, economic, political and cultural linkages. Establishing and developing a broad and heterogeneous socio-economic network is in fact crucial to protecting, supporting and fostering radical innovations. In general it is considered important to involve different groups of insiders and outsiders (in relation to the regime), incumbent and new actors, in order to build fruitful relations in a network and between the network and the outside context.

Fourth, an experimental- and learning-based attitude is required. Since we are dealing with highly complex and uncertain innovations, the process to socially and societally embed them cannot be based on a preconceived and fixed solution. In this sense the societal embedding process should be seen as a path based on exploring, searching and learning. From this perspective it is clear that a crucial role for strategic designers is the designing of the sequences of socio-technical experiments (as Labs, Windows and Agents of change) that could potentially lead to a gradual societal embedding of the PSS innovation.

Finally, the adoption of an experimental- and learning-based based approach requires a flexible and dynamic management attitude. A project vision is not a static outcome to be achieved; it is continuously adjusted as a result of what is learnt by actors during the societal embedding process (in particular during sociotechnical experiments). Hence, since the transition strategy is oriented towards the achievement of the project vision, adjustments in the project vision lead to modifications in the transition strategy. Even the network of actors involved in the societal 
embedding process is dynamic: the composition, as well as the required tasks for each actor, continuously evolve in time, as the different phases in the transition path require different network compositions. For instance the process of networking in local socio-technical experiments differs from networking in scaling-up. In other words we are dealing with a flexible and dynamic process characterised by the mutual adjustment of the long-term vision, the transition path and the actors' network (mutual adjustment as a result of the learning processes). It is therefore crucial for strategic designers to adopt a flexible and dynamic approach to managing this continuous adjustment and redirection.

\subsubsection{New design capabilities required}

Based on the explanations above this new design approach requires innovative design skills as described below.

- Translating the PSS concept vision into a transition strategy: Strategic designers must learn to translate a PSS concept vision into the steps needed to support its implementation and scaling-up. In other words they must learn to design transition paths: the sequence of steps between the present situation without and a future situation with the PSS implemented. Within these transition paths a crucial role is played by socio-technical experiments. Strategic designers must therefore learn to design these kinds of experiments and in particular how to design sequences of experiments with the aim of learning and exploring how to improve and refine the PSS innovation and how to favour its societal embedding. The design of the PSS concept should be combined with the strategic identification of the steps to be undertaken in order to orient the innovation development towards the achievement of the vision itself

- Designing the actor network configurations needed to support the societal embedding process: Strategic designers must learn to identify the proper actors to be involved in the various phases of the process: to design a dynamic network of actors in which the composition, as well as the required tasks of each actor, continuously evolve in time. Moreover strategic designers should be capable of adopting a broad system approach and think not only in terms of the PSS value chain (producers, partners, suppliers, users, etc.), but also about the actors that have the power and willingness to directly influence the dominant regime (for example ministries, policy-makers and politicians, and incumbent organisations) as well as the actors that may indirectly influence it (for example NGOs, societal pressure groups and the media). Strategic designers should thus be able to act as networkers (capable of establishing bridges and links between different actors) and as negotiator/facilitators (capable of managing controversies and conflicts within the network)

- Facilitating the building up of a shared project vision and action plan: Strategic designers must learn to facilitate the strategic conversation between 
the actors involved, in order to develop (and adapt in time) a shared project vision and action plan. Strategic designers should therefore be able to facilitate a participatory approach, involving a variety of stakeholders in discussing, negotiating, co-creating and developing alternatives. It is therefore crucial that strategic designers are able to organise the complexity of the information that must be exchanged and support effective communication activities among stakeholders; encourage and stimulate the various actors in taking part in strategic conversations; and manage the diversity of their expectations as well as their negotiation and alignment. These skills are thus fundamental: being a communicator (capable of effectively illustrating complex information such as project visions and action plans) and a negotiator (capable of facilitating the convergence of actors' expectations)

- Managing the dynamic adaptation of the societal embedding process: Strategic designers should learn to manage the continuous adaptation and evolution of the project vision, the transition path and the actor network. The project vision is not a static result to be achieved, the transition strategy is not a fixed roadmap to be strictly followed, and the composition of the actor network is not pre-defined: they continuously evolve in time in relation to what is learnt by the actors. It is therefore crucial for strategic designers to be able to dynamically manage the interactions between project vision, transition strategy and actors' network, not as a project with a fixed result, but rather as an open search and learning process. As a result it is necessary to break with the dichotomy between designing and implementing: design, development and implementation should be carried out simultaneously and in continuous interaction

This strategic design approach has been recently applied in several research projects coordinated by the unit of research Design and system Innovation for Sustainability (DIS) of Politecnico di Milano. One of these, run in collaboration with the South African Cape Peninsula University of Technology (CPUT), is called Cape Town Sustainable Mobility Project. The following section briefly describes the design process and approach adopted in the project and the main results achieved.

\subsubsection{A design experience: the Cape Town Sustainable Mobility project \\ Background}

The project involves, as main actors, Shonaquip (a small South African company producing wheelchairs and mobility equipment for disabled people), BEN Bikes (a local association aimed at promoting sustainable mobility projects and initiatives), the Cape Peninsula University of Technology (CPUT), and Politecnico di Milano (Polimi). The aim of the project is to introduce and diffuse a sustainable mobility PSS for the disabled and elderly people in the suburban areas of Cape Town. 
In particular the system is expected to offer disabled and elderly people increased mobility services from their homes to the nearest public transport stops, or to local schools, hospitals, etc. Technically, the mobility system is designed around a solar, electric and human-powered light vehicle ${ }^{5}$ prototyped by Politecnico di Milano and IPSIA 'A. Ferrari' Maranello in 2006. This mobility system is especially conceived to create benefits in suburbs such as those in Cape Town, which are often characterised by substantial mobility problems due to a lack of high-quality public transport services. The initial PSS concept was developed by Hazal Gumus for her Master's degree thesis (Gumus 2009), conducted in collaboration between Politecnico di Milano and CPUT. The thesis project raised the interest of Shonaquip and in July 2009, a process to socially embed the PSS innovation officially started.

\section{Incubation}

The process began with the first formalisation of the project vision, on the basis of the initial PSS concept, by Polimi, Shonaquip and CPUT. The aim was to translate the project idea into a set of visual artefacts that clearly and effectively communicated the PSS innovation's characteristics and its potential benefits to different types of actors. A set of tools was used to support this task: ${ }^{6} 1$ ) the offering diagram, to visualise which customer needs are addressed by the PSS; 2) the interaction table, to visualise how the PSS providers deliver the service and how the customers are to be satisfied; 3 ) the system map, to visualise the structure of the value chain; and 4 ) the sustainability diagram, to visualise the environmental, socio-ethical and economic benefits.

The next step was the development of a draft action plan, to identify the main steps between the present situation and a future situation with the PSS implemented. This activity was performed by Polimi in interaction with Shonaquip and CPUT. The following step was the identification of actors to be involved in strategic discussions. It was decided to first include a restricted group of actors (the ones considered crucial to start discussing and strengthening the PSS concept and the action plan) and later extend participation to a wider variety of actors such as the Cape Town municipality, the local public transport company, and local media. Actors initially involved were potential users, local citizens, technology experts from CPUT, and two local NGOs: Disability Workshop Enterprise Development, DWDE (active in providing job opportunities to disabled people), and the Reconstructed Team (an association aimed at reintegrating into society former drug addicts and criminals).

To accomplish this, a two-day workshop was organised in September 2009 where the first day focused on discussing and adjusting the project vision and the second day focused on the action plan. In the workshop, the PSS concept and the transition

5 Designed by Fabrizio Ceschin (the author) for his Master's degree thesis, Politecnico di Milano, Faculty of Design, 2006.

6 See Part 1, Chapter 4, in this volume for full explanations of these tools. 
path were adjusted, implementation barriers were identified, new actors were recommended, and actors' tasks were agreed upon.

In phase 2 the socio-technical experiments were designed and implemented.

The first experiment was implemented in the Athlone district (Bridgetown), in collaboration with the Reconstructed Team, and was aimed only at testing and improving the technical and usability aspects of the PSS innovation. An existing rickshaw was used to test the service of transporting the elderly in the neighbourhood, involving them in identifying critical issues and suggesting potential improvements, and subsequently, once the vehicle prototype was completed, a series of technical tests took place (Figure 4.3).

\section{Figure 4.3 First socio-technical experiment: photo taken during technical test of the vehicle (August 2011) \\ Source: Ceschin $2012 \mathrm{a}$}

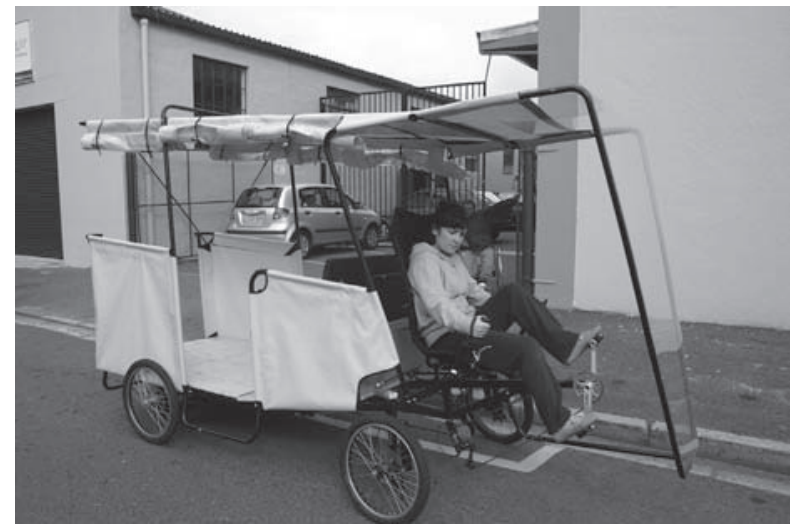

After settling the vehicle's technical problems and collecting the first feedback on the service, a second experiment (much more articulated) was implemented in collaboration with BEN Bikes in October 2011 and is still running. It was designed and organised in order to act as a Lab, Window and Agent of Change. The following paragraphs will respectively illustrate these three 'functions'.

The first aim of the experiment was to test and improve the PSS innovation (experiment as Lab). A service for the transportation of elderly, sick and disabled people from their home to any point of interest around the Lavender Hill community (such as to the hospital, church or the post office) was implemented and is currently running. The main role of the local BEN Bikes centre is to manage the service as well as take care of vehicle maintenance. The experiment is currently used to: test and improve the vehicle; test and improve the service (using questionnaires and semi-structured interviews); test and improve the PSS configuration (in terms of stakeholder value chain and business model); and identify barriers (on multiple dimensions including socio-cultural and regulative). For the latter, various actors 
(such as the local community, local institutions and NGOs) are involved to express their opinions, remarks and suggestions, in order to identify further potential barriers not already identified in the previous steps. It must be stressed that the approach adopted is aimed at favouring broad participation in the design choices. All the involved actors (from the potential users to the local community and the local institutions) are asked not only to evaluate and provide feedback on the project, but are also stimulated to propose adjustments and alternatives.

The experiment was also designed to raise interest in the innovation project and attract and enrol new potential users and other relevant actors (experiment as Window). With respect to this the BEN Bikes centre has been conceived as a sort of 'open gallery' to allow visitors to see, touch and acquire information about the project. Interested people can freely visit the centre and better understand the features of the project and its environmental, socio-ethical and economic benefits. Moreover demonstration visits are organised with specific actors (for example potential users but also potential future partners, local institutions, etc.). BEN Bikes personnel have been trained to be able to effectively describe the project and in particular to illustrate the potential advantages for different kinds of actors. This was considered particularly important by project promoters because there was the need not only to disseminate information about the project but also to stimulate changes in actors' behaviour and routines (for example stimulate potential users to reflect on their mobility habits and consider the benefits that the solution could provide to them). This is clearly connected to the third function of the experiment: experiment as Agent of Change.

The experiment was also conceived to stimulate changes in actors' behaviour and habits and create favourable conditions for the introduction and diffusion of the PSS (experiment as an Agent of Change). Therefore, in October 2011 an event for relevant actors was organised. The aim of this event was to officially launch the experiment, illustrate the potential future developments, and discuss with invited actors how to support and accelerate the project. The event took place at the Lavender Hill BEN Bikes centre.

The actors invited to the event were the Cape Town municipality (in particular the Transport department and the Environmental Resource Management department), because of their potential interest in the project and their direct influence on local transport regulation; local actors potentially interested in implementing specific mobility services based on the MULO vehicle (in particular local schools and the local clinic Philiza Abafazi Bethu); and local media. The results of the event were positive. First, local actors evaluated the project as valuable for local communities, because of its potential to bring tangible economic, environmental and socio-ethical benefits. Second, one of the actors involved, the local clinic, stated its interest in implementing a service for the transportation of patients as soon as possible. Third, the Transport department of Cape Town confirmed its interest in strengthening synergies between the PSS and the suburban bus lines. In addition the Transport department stated that it put meetings in its agenda to discuss the policy measures needed to support and foster the particular vehicle typology adopted in the PSS. 
Because the second socio-technical experiment is still ongoing, it is currently not possible to develop definitive overall conclusions regarding the entire Sustainable Mobility project. Nevertheless, it is possible to say that the whole journey strengthened the stakeholder network, served to refine and improve the PSS concept, and created important opportunities for future developments.

\subsection{Towards a new way of designing and implementing eco-efficient PSSs}

On the basis of the hypothesised strategic design approach, and taking into consideration the intermediate results of the Cape Town Sustainable Mobility project, a first tentative design and implementation process to support the introduction and diffusion of eco-efficient PSSs is proposed.

Figure 4.4 provides an overview of this process (Ceschin and Raven 2011; Ceschin 2012a). It is proposed that it is used by strategic designers, project managers and consultants to support and guide a company (or a small network of actors) in managing and enhancing the societal embedding process of an eco-efficient PSS innovation. In particular the approach facilitates the adoption of an experimental-, learning-, and network-based design and management attitude, with the aim of increasing the chances of successfully introducing and diffusing eco-efficient PSSs. The whole process comprises five activity clusters and three phases. The activity clusters are the following:

- Vision building and expectation shaping (WHAT the project network wants to achieve). Activities related to building up and formalising a project vision shared among the actors and social groups involved in the project

- Action plan development ( $H O W$ the vision could be achieved). Activities related to translating the vision into the steps needed to support and favour societal embedding of the PSS concept

- Actors' network establishment and development (WHO has to be involved in the project). Activities related to establishing, managing and developing the network around the project

- Action plan implementation ( $D O$ what is planned). Activities related to implementing the actions identified in the strategic plan

- Monitoring, evaluation and learning ( $L E A R N$ from activities undertaken). Activities related to monitoring and evaluating the transition process and identifying the adjustments to be carried out

The phases consist of incubation, socio-technical experimentation and scaling-up, which are briefly presented in the following sections (Ceschin and Raven 2011; Ceschin 2012a). 
Figure 4.4 Process to support the societal embedding of eco-efficient PSSs Source: author

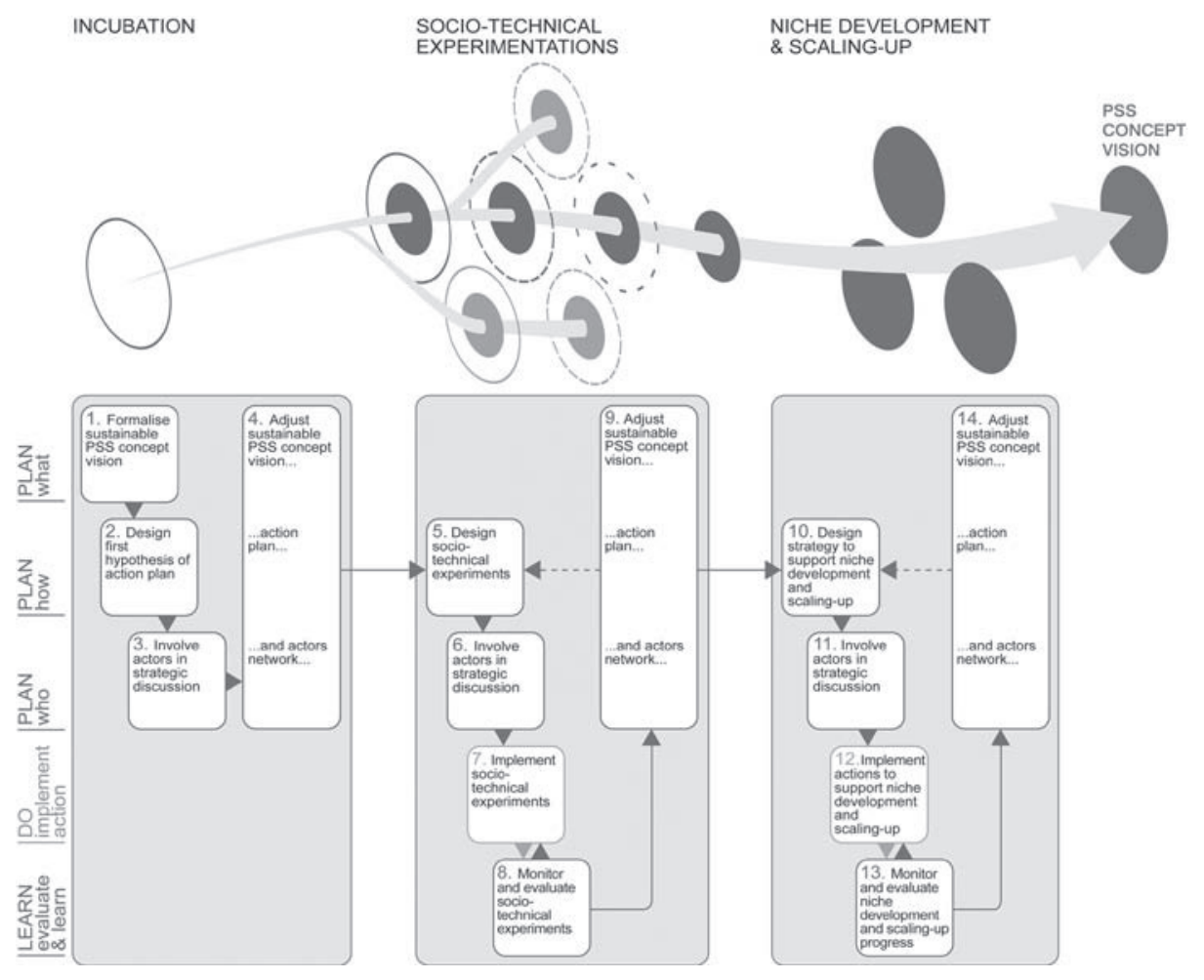

\subsubsection{Phase 1: incubation}

The incubation phase sets up the conditions to initiate the societal embedding process. The starting point is an eco-efficient PSS concept developed by one or more PSS promoters. The first step is to formalise the project vision in order to communicate in a clear and effective way the aims of the project, the main characteristics of the PSS innovation, and its potential (environmental, economic and/or socio-ethical) benefits.

The next step is to explore how the concept could be socially embedded. This involves making a comparison between the present situation without the PSS and the future situation in which the PSS concept is implemented. It is essential to adopt a strategic attitude in order to identify the short and medium-term actions to be undertaken in order to create the most favourable operable conditions. Actors potentially interested in the concept, as well as actors that could give protection and support to the innovation, are identified. This step produces a first formalised draft action plan (identification of the actions to be undertaken, the actors to be involved, and their roles). 
The third step is the involvement of the identified stakeholders in strategic discussions: in this stage meetings and workshops are organised with the actors previously identified. The aim is to collect and confront the different actors' expectations, discuss and adjust both the project vision and the action plan, and achieve a common consensus.

As a result of these meetings and workshops the project vision, the action plan and the actor network are adjusted. The output of this phase is the establishment of a project network that agrees on a project vision and on an action plan.

\subsubsection{Phase 2: socio-technical experimentation}

In this phase small-scale socio-technical experiments are implemented in real settings with the aim of learning and exploring how to improve the PSS innovation and how to contribute to its societal embedding.

This phase begins by designing the experiments such that they are protected from the mainstream competition environment and act as Labs, Windows, and Agents of Change (see previous sections). The design of the experiment includes: the identification of an implementation area and the appropriate financial and socio-institutional protections, the technical aspects of the PSS, as well as identification of the socio-economic organisation to protect and support the innovation (identification of actors to be involved and related tasks).

During the experiment monitoring and evaluation activities are undertaken. These include the experiment (technical and usability aspects, acceptability of the PSS by the various social groups involved in the project, implementation and diffusion barriers, etc.); the actors directly and indirectly involved (their roles, behaviours, expectations, conflicts and convergences); the project vision agreed on and the action plan (and their evolution and adjustment in time).

Evaluation results are then translated into new actions. Through a learningby-doing approach, the evaluation may lead to an adjustment of the experiment, action plan and the broader project vision, as well as increased understanding of the need for contextual changes and ways to achieve them.

Following this process, different experiments can be executed in different contexts and/or testing new functions.

\subsubsection{Phase 3: niche development and scaling-up}

In this phase the aim is to increase momentum of the PSS innovation (and the related new practices, behaviours and institutions) and begin to influence the socio-technical regime. It is a process that leads the innovation to increasingly become part of the mainstream way in which a societal satisfaction is delivered.

The first step is the identification of appropriate actions to enhance the development and reinforcement of the pathway of experiments. It is essential to link the PSS innovation to a broader context, in order to make it relevant beyond the local scale. Key issues are: 
- To repeat the experiments in other contexts and create synergies with similar projects and initiatives. The aim is to share experiences and stimulate and reinforce network building on a broader scale (e.g. within a sector or at a national level)

- To disseminate information/project results and stimulate media attention at a national level

- To stimulate actors at a strategic level to influence the socio-technical context in order to create the most favourable conditions for the scaling-up of the PSS innovation

In sum, the aim is to establish deeper linkages with relevant political, industrial and social actors: those that have the power and willingness to directly influence the dominant culture, practices and institutions; ${ }^{7}$ those that (in)directly may influence the regime because they have an interest in embedding new sustainable practices; those that can spread information on the PSS innovations; and those that may support the scaling-up of the innovation, such as potential industrial partners, industrial associations or consortia.

During the process monitoring and evaluation activities continuously take place. Evaluation targets include the progress of niche development and scalingup (e.g. connections with other experiments, enrolment of new actors, dissemination of project results, connections with regime actors, and introduction of the PSS innovation in niche markets), the actors involved, the project vision and the action plan. The evaluation process can lead to adjustment of the actions to favour niche development and scaling-up, as well as to re-orient the project vision and adjust the actor network and the action plan.

\subsection{Conclusions}

Eco-efficient PSS innovation represents a valuable concept for enhancing company competitiveness and at the same time providing environmental benefits. However, these innovations are in most cases radical, and their introduction and diffusion usually encounter the opposition of existing cultural, corporate and regulative barriers. Hence, if immediately exposed to the mainstream market environment, it is highly probable they will not survive. An important challenge is therefore not only to conceive sustainable PSS concepts, but also to understand the contextual conditions in which they are introduced and explore the most suitable strategies and development pathways to embed these concepts in society. Building upon insights from the transition studies field, this chapter put forward a conceptual framework for the introduction and scaling-up of eco-efficient PSSs. A crucial role is given to 
the implementation of sequences of socio-technical experiments, partially protected spaces where broad networks of actors incubate, test, develop and bring the innovation to maturity without the direct pressure coming from the market environment. Theoretical and empirical evidence supports the proposal that, in order to effectively contribute to transition processes, socio-technical experiments should be conceived as Labs, Windows and Agents of Change.

Strategic design could thereby play a role not only in generating eco-efficient PSS concepts, but also in designing transition paths to support and facilitate the introduction and scaling-up of the concept itself. The chapter also discussed the new design approach and new design capabilities required by designers to operate at such a level.

\section{References}

Akrich, M. (1992) 'The Description of Technological Objects', in W. Bijker and J. Law (eds.) Shaping Technology/Building Society: Studies in Socio-Technical Change (Cambridge, USA: MIT Press).

Aurich, J.C., Fuchs, C., and C. Wagenknecht (2006) 'Life cycle oriented design of technical Product-Service Systems', Journal of Cleaner Production 14.17: 1480-1494.

Berkhout, F. (2006) 'Normative expectations in systems innovation'. Technology Analysis \& Strategic Management 18.3: 299-311.

Björgvinsson, E., Ehn, P. and P.A. Hillgren (2010) 'Participatory design and "democratizing innovation"', in: Proceedings of the Participatory Design Conference (PDC), Sydney, Australia 29 November - 3 December 2010.

Brezet, H., Bijma, A.S., Ehrenfeld, J., and S. Silvester (2001) The design of eco-efficient services: Methods, tools and review of the case study based 'Designing eco-efficient Services' project, report for Dutch Ministries of Environment (VROM).

Brown, H.S., and P.J. Vergragt (2008) 'Bounded socio-technical experiments as agents of systemic change: The case of a zero-energy residential building', Technological Forecasting \& Social Change 75: 107-130.

Brown, H.S., Vergragt, P.J., Green, K., and L. Berchicci (2003) 'Learning for Sustainability Transition Through Bounded Socio-Technical Experiments in Personal Mobility', Technology Analysis \& Strategic Management 13.3: 298-315.

Callon, M. (1991) 'The Dynamics of Techno-Economic Networks', in R. Coombs, P. Saviotti and V. Walsh (eds.) Technical Change and Company Strategies (London, UK: Academic Press).

Callon, M., Laredo, P., and V. Rabeharisoa (1992) 'The Management and Evaluation of Technological Programmes and the Dynamics of Techno-Economic Networks', Research Policy 21.3: 215-236.

Ceschin, F. (2010) 'How to facilitate the implementation and diffusion of sustainable Product-Service Systems? Looking for synergies between strategic design and innovation sciences', in Ceschin, F., Vezzoli, C. and Zhang, J. (eds.), Sustainability in design: now! Challenges and opportunities for design research, education and practice in the XXI century. Proceedings of the Learning Network on Sustainability (LeNS) conference (vol. 1), Bangalore, India, 29 September - 1 October 2010 (Sheffield, UK: Greenleaf Publishing). 
Ceschin, F. (2012a) The introduction and scaling up of sustainable Product-Service Systems: A new role for strategic design for sustainability. $\mathrm{PhD}$ thesis (Milan, Italy: Politecnico di Milano).

Ceschin, F. (2012b) 'Critical Factors for Managing the Implementation and Diffusion of EcoEfficient Product-Service Systems: Insights from Innovation Sciences and Companies' Experiences', Journal of Cleaner Production doi:10.1016/j.jclepro.2012.05.034.

Ceschin, F. and R.P.J.M. Raven (2011) 'Managing the introduction and scaling-up of sustainable Product-Service Systems: Towards a system innovation approach for practitioners', working paper.

Ceschin, F., and C. Vezzoli (2010) 'The Role of Public Policy in Stimulating Radical Environmental Impact Reduction in the Automotive Sector: The Need to Focus on Product-Service System Innovation', Int. J. Automotive Technology and Management 10.2/3: 321-341.

Ceschin, F., Vezzoli, C., and P. Vergragt (2011) 'Small Scale Socio-Technical Experiments as Stepping Stones for Eco-Efficient Product-Service Systems Diffusion: a New Role for Strategic Design for Sustainability', in: J. Hesselbach, and C. Herrmann (eds.) Functional Thinking for Value Creation. Proceedings of the 3rd CIRP International Conference on Industrial Product Service Systems, Technische Universität Braunschweig, Braunschweig, Germany, 5-6 May 2011 (Berlin Heidelberg: Springer): 111-116.

De Laat, B. (1996) Script for the Future: Technology Foresight, Strategic Analysis and SocioTechnical Networks: the Confrontation of Script Based Scenarios. PhD Thesis, University of Amsterdam.

Geels, F. (2002) 'Technological Transitions as Evolutionary Reconfiguration Processes: a Multilevel Perspective and a Case-Study', Research Policy 31.8/9: 1257-1274.

Geels, F.W., and R.P.J.M. Raven (2006) 'Non-linearity and expectations in niche-development trajectories: Ups and downs in Dutch biogas development (1973-2003)', Technology Analysis \& Strategic Management 18: 375-392.

Gumus, H. (2009) Kanga: a sustainable system design for the transportation of learners with disabilities in Cape Town-South Africa, Master's degree thesis, Politecnico di Milano, Faculty of Design.

Hall, P. (1993) 'Policy Paradigms, Social Learning and the State: The Case of Economic Policymaking in Britain', Comp. Polit. 25.3: 275-96.

Hegger, D.L.T., van Vliet, J., and B.J.M. van Vliet (2007) 'Niche Management and its Contribution to Regime Change: The Case of Innovation in Sanitation', Technology Analysis \& Strategic Management 19: 729-746.

Hoogma, R. (2000) Exploiting Technological Niches: Strategies for Experimental Introduction of Electric Vehicles, PhD Thesis (Enschede, NL: Twente University Press).

Hoogma, R., and J.W. Schot (2001) 'How innovative are users? A critique of learning-by-doing and-using', in: R. Coombs, K. Green, A. Richards and V. Walsh (eds.), Technology and the Market (Cheltenham/Massachusetts: Edward Elgar): 216-233.

Hoogma, R., Kemp, R., Schot, J., and B. Truffer (2002) Experimenting for Sustainable Transport: The Approach of Strategic Niche Management (London/New York: Spon Press).

Kemp, R., and J. Rotmans (2004) 'Managing the Transition to Sustainable Mobility', in B. Elzen, W. Geels, and K. Green (eds.), System Innovation and the Transition to Sustainability: Theory, Evidence and Policy (Cheltenham, UK, Northampton, USA: Edward Elgar Publishing).

Kemp, R., Schot, J., and R. Hoogma (1998) 'Regime Shifts to Sustainability Through Processes of Niche Formation: the Approach of Strategic Niche Management', Technology Analysis \& Strategic Management 10.2: 175-195.

Kemp, R., A. Rip and J. Schot (2001) 'Constructing Transition Paths Through the Management of Niches', in R. Garud and P. Karnøe (eds.), Path Dependence and Creation (London, UK: Lawrence Erlbaum). 
Laredo, P., and P. Mustar (1996) 'The Techno-Economic Network, a Socio-Economic Approach to State Intervention in Innovation', in R. Coombs, A. Richard, P. Saviotti, and V. Walsh (eds.), Technological Collaboration (Cheltenham: Edward Elgar).

Laredo, P., Jolivet, E., Shove, E., Raman, S., Rip, A., Moors, E., Poti, B., Shaeffer, G.J., Penan, H., and C.E. Garcia (2002) Management tools and management framework for assessing the potential long term S\&T options to become embedded in society. Socrobust Final report.

Latour, B. (2000) 'PROTEE Principles: Theoretical Background', in M. Duret et al. (eds.), Final report of the PROTEE project (Paris, France).

Luiten, H., Knot, M., and T. van der Horst (2001) 'Sustainable product service-systems: the Kathalys method' paper presented at the Second International Symposium On Environmentally Conscious Design And Inverse Manufacturing, 2001.

Lynn, G.S., Morone, J.G., and A.S. Paulson (1996) 'Marketing and Discontinuous Innovation: the Probe and Learn Process', California Management Review 38: 8-37.

Manzini, E., Collina, L., and S. Evans (eds.) (2004) Solution oriented partnership (Cranfield, UK: Cranfield University).

Maxwell, D., Sheate, W., and R. van der Vorst (2006) 'Functional and systems aspects of the sustainable product and service development approach for industry', Journal of Cleaner Production 14.17: 1466-1479.

Quist, J., Rammelt, C., Overschie, M. and G. de Werk (2006) 'Backcasting for Sustainability in Engineering Education: the case of Delft University of Technology', Journal of Cleaner Production 14.9/11: 868-876.

Raven, R.P.J.M. (2005) Strategic Niche Management for Biomass, PhD thesis (Eindhoven: Technische Universiteit Eindhoven).

Raven, R.P.J.M., Heiskanen, E., Lovio, R., Hodson, M., and B. Brohmann (2008) 'The contribution of local experiments and negotiation processes to field-level learning in emerging (niche) technologies', Bulletin of Science, Technology and Society 28.6: 464-477.

Raven, R.P.J.M., van den Bosch, S., and R. Waterings (2010) 'Transition and strategic niche management: towards a competence kit for practitioners', International Journal of Technology Management 51.1: 57-74.

Rip, A., and R. Kemp (1998) 'Technological Change', in S. Rayner and E.L. Malone (eds.), Human Choice and Climate Change, Vol. 2 (Columbus: Batelle Press): 327-399.

Rotmans, J., Kemp, R., and M.B.A. Asselt (2001) 'More evolution than revolution: transition management in public policy', Foresight 3: 15-32.

Schot, J.A., and R. Hoogma (1996) De Invoering van Duurzame Technologies: Strategisch Niche Management als Beleidsinstrument, DTO Programme (Delft: Delft University of Technology).

Schot, J., and F. Geels (2008) 'Strategic Niche Management and Sustainable Innovation Journeys: Theory, Findings, Research Agenda, and Policy', Technology Analysis \& Strategic Management 20.5: 537-554.

Tukker, A., and U. Tischner (2006a) 'Product-Services as a Research Field: Past, Present and Future: Reflections from a Decade of Research', Journal of Cleaner Production 14.17: 1552-1556.

Tukker, A., and U. Tischner (2006b) 'A practical guide for PSS development', in A. Tukker and U. Tischner (eds.), New Business for Old Europe: Product Services, Sustainability and Competitiveness (Sheffield, UK: Greenleaf Publishing).

Tukker, A., and C. van Halen (2003) Innovation scan product service combination: manual (Delft: TNO-STB).

Van de Kerkhof, M., and A. Wieczorek (2005) 'Learning and Stakeholder Participation in Transition Processes Towards Sustainability: Methodological Considerations' Technological Forecasting \& Social Change 72: 733-747. 
Van de Poel, I. (2000) 'On the role of outsiders in technical development', Technology Analysis and Strategic Management 12.3: 383-397.

Van den Bosch, S. (2010) Transition Experiments. Exploring societal changes towards sustainability, $\mathrm{PhD}$ thesis (Rotterdam: Erasmus Universiteit Rotterdam).

Van den Bosch, S., and J. Rotmans (2008) Deepening, Broadening, and Scaling up: towards a Conceptual Framework for Transition Experiments (Delft, The Netherlands: Knowledge Centre for Sustainable System Innovations and Transitions, KCT).

Van der Laak, W.W.M., Raven, R.P.J.M., and G.P.J. Verbong (2007) 'Strategic niche management for biofuels: Analysing past experiments for developing new biofuel policies', Energy Policy 35: 3213-3225.

Van Halen, C., Vezzoli, C., and R. Wimmer (eds.) (2005) Methodology for Product Service System: How to develop clean, clever and competitive strategies in companies (Assen, The Netherlands: Van Gorcum).

Van Lente, H. (1993) 'Chapter 6: construction by expectations', in: van Lente, H. (ed.), Promising Technology: The dynamics of Expectations in Technological Developments (Twente: Twente University): 177-204.

Vezzoli, C. (2010) System design for sustainability: Theory, methods and tools for a sustainable 'satisfaction-system' design, 2nd edn (Milan, IT: Maggioli editore).

Vezzoli, C., Ceschin, F., and R. Kemp (2008) 'Designing transition paths for the diffusion of sustainable system innovations: A new potential role for design in transition management?', in C. Cipolla and P.P. Peruccio (eds.), Changing the change. Design, visions, proposals and tools, Changing the change conference, Turin, Italy, 10-12 July 2008 (Turin, Italy: Umberto Allemandi).

Vezzoli, C., Ceschin, F., and S. Cortesi (2009) Metodi e strumenti per il life cycle design. Come progettare prodotti a basso impatto ambientale (Rimini, Italy: Maggioli).

Weber, M., Hoogma, R., Lane, B., and J. Schot (1999) Experimenting with Sustainable Transport Innovations: A Workbook for Strategic Niche Management (Twente: Universiteit Twente). 